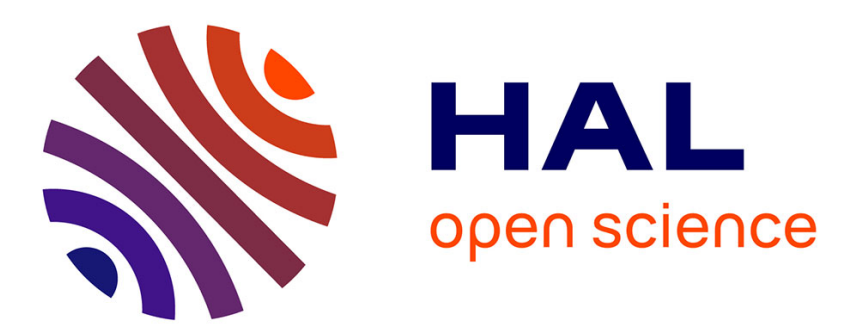

\title{
Air heat exchangers with long heat pipes: experiments and predictions
}

H. Hagens, F.L.A. Ganzevles, C.W.M. van Der Geld, M.H.M. Grooten

\section{To cite this version:}

H. Hagens, F.L.A. Ganzevles, C.W.M. van Der Geld, M.H.M. Grooten. Air heat exchangers with long heat pipes: experiments and predictions. Applied Thermal Engineering, 2007, 27 (14-15), pp.2426. 10.1016/j.applthermaleng.2007.03.004 . hal-00498948

\section{HAL Id: hal-00498948 https://hal.science/hal-00498948}

Submitted on 9 Jul 2010

HAL is a multi-disciplinary open access archive for the deposit and dissemination of scientific research documents, whether they are published or not. The documents may come from teaching and research institutions in France or abroad, or from public or private research centers.
L'archive ouverte pluridisciplinaire HAL, est destinée au dépôt et à la diffusion de documents scientifiques de niveau recherche, publiés ou non, émanant des établissements d'enseignement et de recherche français ou étrangers, des laboratoires publics ou privés. 


\section{Accepted Manuscript}

Air heat exchangers with long heat pipes: experiments and predictions

\section{APPLIED}

THERMAL

ENGINEERING

H. Hagens, F.L.A. Ganzevles, C.W.M. van der Geld, M.H.M. Grooten

PII:

S1359-4311(07)00084-1

DOI:

10.1016/j.applthermaleng.2007.03.004

Reference:

ATE 2114

To appear in:

Applied Thermal Engineering

Received Date: $\quad 16$ October 2006

Revised Date: $\quad 28$ February 2007

Accepted Date: $\quad 1$ March 2007

Please cite this article as: H. Hagens, F.L.A. Ganzevles, C.W.M. van der Geld, M.H.M. Grooten, Air heat exchangers with long heat pipes: experiments and predictions, Applied Thermal Engineering (2007), doi: 10.1016/ j.applthermaleng.2007.03.004

This is a PDF file of an unedited manuscript that has been accepted for publication. As a service to our customers we are providing this early version of the manuscript. The manuscript will undergo copyediting, typesetting, and review of the resulting proof before it is published in its final form. Please note that during the production process errors may be discovered which could affect the content, and all legal disclaimers that apply to the journal pertain. 


\title{
Air heat exchangers with long heat pipes: experiments and
}

\author{
predictions
}

\begin{abstract}
H. Hagens ${ }^{\mathrm{a}}$, F.L.A. Ganzevles ${ }^{\mathrm{b}}$, C.W.M. van der Geld ${ }^{\mathrm{b}, *}$, M.H.M. Grooten ${ }^{\mathrm{b}}$
\end{abstract}
${ }^{\text {a }}$ VDL Klima b.v. Meerenakkerweg 30, 5652 AV Eindhoven, Netherlands.

${ }^{\mathrm{b}}$ Department of Mechanical Engineering, Technische Universiteit Eindhoven. Postbus 513, 5600 MB Eindhoven, Netherlands.

\begin{abstract}
This paper presents measurements and predictions of a heat pipe-equipped heat exchanger with two filling ratios of $\mathrm{R} 134 \mathrm{a}, 19 \%$ and $59 \%$. The length of the heat pipe, or rather thermosyphon, is long $(1.5 \mathrm{~m})$ as compared to its diameter $(16 \mathrm{~mm})$. The airflow rate varied from 0.4 to $2.0 \mathrm{~kg} / \mathrm{s}$. The temperatures at the evaporator side of the heat pipe varied from 40 to $70^{\circ} \mathrm{C}$ and at the condenser part from 20 to $50^{\circ} \mathrm{C}$. The measured performance of the heat pipe has been compared with predictions of two pool boiling models and two filmwise condensation models. A good agreement is found. This study demonstrates that a heat pipe equipped heat exchanger is a good alternative for air-air exchangers in process conditions when air-water cooling is impossible, typically in warmer countries.
\end{abstract}

Keywords : finned tube, heat exchanger, heat pipe, R-134a, thermosyphon

\footnotetext{
* Corresponding Author. Tel.: +31 40 2472923, Fax: +31 40 2475399, E-mail: c.w.m.v.d.geld@tue.nl
} 


\section{Nomenclature}

A surface area, $\mathrm{m}^{2}$

Bo Bond number, $B o=\sqrt{\rho_{\mathrm{f}} g d^{2} / \sigma}$,

$c_{p} \quad$ heat capacity at constant pressure, $\mathrm{J} / \mathrm{kgK}$

d diameter, $\mathrm{m}$

$d_{i} \quad$ inner pipe diameter, $\mathrm{m}$

$D_{\mathrm{h}} \quad$ hydraulic diameter, $\mathrm{m}$

$F_{e} \quad$ filling degree, -

$g$ acceleration due to gravity, $\mathrm{m} / \mathrm{s}^{2}$

$h \quad$ fin distance, $\mathrm{m}$

L length, m

$\dot{m} \quad$ mass flow rate, $\mathrm{kg} / \mathrm{s}$

$M \quad$ molecular weight, $\mathrm{kg} / \mathrm{kmol}$

$\mathrm{Nu} \quad$ Nusselt number,

$p \quad$ pressure, $\mathrm{Pa}$

$p_{\mathrm{r}} \quad$ reduced pressure, -

Pr Prandtl number, -

$q$ heat flux, $\mathrm{W} / \mathrm{m}^{2}$

$Q \quad$ heat flow rate, $\mathrm{W}$

$r \quad$ radius, $\mathrm{m}$

$R \quad$ heat resistance, $\mathrm{K} / \mathrm{W}$

Re Reynolds number, -

$S \quad$ fin distance, $m$ 
T temperature, ${ }^{\circ} \mathrm{C}$

$V \quad$ volume, $\mathrm{m}^{3}$

$W \quad$ distance between pipes, $\mathrm{m}$

Greek

$\alpha \quad$ heat transfer coefficient, $\mathrm{W} / \mathrm{m}^{2} \mathrm{~K}$

$\lambda$ thermal conductivity, $\mathrm{W} / \mathrm{mK}$

$\delta \quad$ thickness, $\mathrm{m}$

$\Delta h_{f g} \quad$ enthalpy of evaporation, $\mathrm{J} / \mathrm{kg}$

$\eta_{\text {fin }} \quad$ fin efficiency, -

$\mu \quad$ dynamic viscosity, Pas

$\rho \quad$ mass density, $\mathrm{kg} / \mathrm{m}^{3}$

$\sigma \quad$ Surface tension coefficient, $N / m$.

$\chi \quad$ geometric correction factor

Subscripts and superscripts
b boiling
c condensation
cond condenser
evap evaporator
f fluid
ff $\quad$ fluid film
i inner 


$\begin{array}{ll}\text { max } & \text { maximum } \\ \text { min } & \text { minimum } \\ \text { o } & \text { outer } \\ \text { tot } & \text { total } \\ \text { v } & \text { vapour } \\ \text { w } & \text { wall } \\ x, y & \text { Cartesian coordinates }\end{array}$




\section{INTRODUCTION}

Stand-alone electricity power generators are usually cooled with ambient air. Standard practice is air-to-air heat transfer or using a tube-in-plate heat exchanger with water as an intermediate medium. In some situations water is not available or ambient temperatures are too high to use ambient air. In those cases heat pipes may provide an alternative for cooling powers in excess of $100 \mathrm{~kW}$. Multiple heat pipes then connect two plate heat exchangers.

The heat transfer in the system is based on the continuous cycle of the vaporization and condensation process. The thermosyphon, or heat pipe if equipped with a wick inside, is heated at the evaporator, which causes evaporation of a part of the fluid. The vapour flows to the condenser, where the fluid condenses while giving off its latent heat, caused by cooling from the outside. The condensate flows back to the heated section along the wall by gravitation or capillarity, which closes the cycle.

Thermosyphons can be used to foster heat transfer between two gas streams [1, 2]. Vasiliev [3,4] gives an overview of applications of heat pipes and thermosyphons, including heat pipes for application in space. Advantages are high heat recovery effectiveness, compactness, no moving parts, light weight, relative economy, no external power requirements, pressure tightness, no cross-contamination between streams and reliability $[5,6]$.

The heat transfer being based on evaporation and condensation, the latent heat of the fluid is an important parameter. The higher the latent heat of a fluid, the higher the 
transfer of heat is at a lower pressure. The working principles of the thermosyphon imply that the fluid should evaporate and condense within the temperature range. Taking the possible application of cooling an electricity generator with ambient air into consideration, the working fluid R-134a is an option. The hot air will be in a range of 40 $-80^{\circ} \mathrm{C}$, the ambient air will be in a range of $-20-50^{\circ} \mathrm{C}$. The refrigerant $\mathrm{R}-134 \mathrm{a}$ sublimates at $-40^{\circ} \mathrm{C}$ and $51 \mathrm{kPa}$, so phase change from liquid to gas only occurs above this temperature [7]. The critical temperature of $\mathrm{R}-134 \mathrm{a}$ is $101.06^{\circ} \mathrm{C}$ [8], which defines the extremes of the temperature range of R-134a, at a critical pressure of $4.06 \mathrm{MPa}$.

Other possible working fluids are ammonia, pentane or water [5]. All these fluids have the advantage over R-134a that they have a higher latent heat, which enhances heat transfer. Unfortunately, the maximum practical temperature limit of ammonia is $50^{\circ} \mathrm{C}$ [9], which is too low for the situation at hand. Water has the risk of freezing at lower temperatures. Pentane could be a useful alternative for R-134a, considering its temperature range from -20 to $120^{\circ} \mathrm{C}$, the higher latent heat and the higher surface tension coefficient $[5,10,11]$. A higher surface tension coefficient has the benefit of lowering the risk of entrainment, which is the most likely occurring limit in the application of the thermosyphon [12]. Other hydrocarbon refrigerants mentioned by Lee et al.[13] are possible working fluids as well. The type of filling fluid and the operational limits will be subject of later research by the present authors.

This paper presents experimental data of air-heat pipe-air heat exchangers with long pipes $(1.5 \mathrm{~m})$ at two filling ratios. Nearly all data found in the literature are for much shorter thermosyphons. The results are compared with those of a model that is based on 
existing correlations of the literature. The results will further be analyzed with the aid of trends measured with a single pipe thermosyphon, as for example those of Noie [14]. Results of this study show which conditions foster application of this novel type of heat exchanger.

\section{EXPERIMENTAL}

A laboratory scale test rig was designed and built to compare the performances of conventional plate-type exchangers (with water as intermediate medium) and heat pipe equipped plate heat exchangers. A range of mass flow rates of ambient air of 0.2-2.5 $\mathrm{kg} / \mathrm{s}$ is possible. The temperature difference between hot and cold sides of the heat pipe may vary up to $60^{\circ} \mathrm{C}$. Let the volume of the evaporator, $V_{\text {evap }}$, be defined as the inner volume of that part of the heat pipe that is in contact with hot air, see Figure 1. It will be quantified, below, as the volume $\pi r_{\mathrm{i}}^{2} L_{\mathrm{evap}}$ with $r_{\mathrm{i}}=7.2 \mathrm{~mm}$ and $L_{\text {evap }}=640 \mathrm{~mm}$. Two filling degrees, $F_{\mathrm{e}}$, as defined in Eq. (1), of the heat pipe with R-134a have been examined $19.0 \pm 0.1 \%$ and $59.0 \pm 0.1 \%$ (for sake of convenience these cases are indicated with $F_{e}=19 \%$ and $F_{e}=59 \%$ in the following):

$$
F_{\mathrm{e}}=\text { (volume of fluid in the tube) } / V_{\text {evap }}
$$

Note that the volume of fluid is the volume of liquid plus the volume that would be obtained if the vapour would be condensed to liquid. In this study, the overall heat transfer and temperature distribution are assessed under mass flow rates of ambient air varying from $0.4 \mathrm{~kg} / \mathrm{s}$ to $2.0 \mathrm{~kg} / \mathrm{s}$. The ambient air temperature varies from $20-50^{\circ} \mathrm{C}$, whereas the hot air flow has temperatures in the range from $40-70^{\circ} \mathrm{C}$. A schematic 
overview of the setup is shown in Figure 1. The upper side is the cold side, where ambient air enters. Up- and downstream of the heat exchanger temperatures are measured with 16 Pt100's (IC Istec ME 1009), with an accuracy of $0.1^{\circ} \mathrm{C}$. The temperatures of four sensors are averaged and the results are denoted as $T_{1}, T_{2}, T_{3}$ and $T_{4}$, see the LHS of Figure 2. At each axial location, four sensors are mounted at $1 / 4$ and $3 / 4$ of the length of the two diagonals of the $645 \times 520 \mathrm{~mm}^{2}$ rectangular duct. The air stream velocity profile was measured and found to be homogeneous. Downstream of the hot section, ten Pt-100 temperature sensors are mounted to investigate the temperature variation over the height of the pipe at the evaporator section. They are mounted vertically at $50 \mathrm{~mm}$ distance from each other and at $117 \mathrm{~mm}$ of the sidewall. The Pt-100 sensors are all calibrated with accuracy better than $0.1^{\circ} \mathrm{C}$ for the temperature range of 0 $-100^{\circ} \mathrm{C}$. The measurement section is thermally insulated to minimize errors in the heat fluxes deduced.

At the entry, dynamic pressure measurement with an orifice gives the air mass flow rate, with an accuracy of $2 \%$. The uncertainties of all measured and calculated parameters are estimated according to [15].

The air heater is a water-air heat exchanger, with $3 \mathrm{~mm}$ spaced vertical fins, which allows a uniform velocity profile upstream of the evaporator. This neutralizes the induced swirl in the airflow caused by the radial fan.

The heat exchanger consists of 4 rows of alternating 14 and 13 vertical copper pipes, see the RHS of Figure 2. These pipes have an outer diameter of $16 \mathrm{~mm}$ and a wall thickness 
of $0.8 \mathrm{~mm}$. The total length of each pipe is $1.5 \mathrm{~m}$, with $0.64 \mathrm{~m}$ in the condenser section and the evaporator section each. The adiabatic length is $0.22 \mathrm{~m}$. This is the distance between the two sections of the airflow in the wind tunnel. The inner surface of each pipe has small spiral grooves, to enhance the heat transfer in evaporation and condensation. The grooves are $0.2 \mathrm{~mm}$ wide and $0.2 \mathrm{~mm}$ deep each, separated $1 \mathrm{~mm}$, under an angle of $25^{\circ}$ with the vertical. The distance between the pipes in a row is 36.5 $\mathrm{mm}$. The rows are $27.5 \mathrm{~mm}$ apart and the total length in airflow direction of the aluminium fins including the 4 rows is $114.5 \mathrm{~mm}$, see Figure 2. At the top of each row, the pressure is measured with a WIKA type RB manometer, at a frequency of $100 \mathrm{~Hz}$, with an accuracy of $1 \%$ after calibration. The range of the manometers is $0-10 \mathrm{MPa}$. The saturation temperature of R134a is given by the Antoine relation (2) obtained from data from NIST [8] with temperatures in degrees Celsius and pressure in $\mathrm{kPa}$

$$
T=B /\left\{A-\ln \left(p_{\mathrm{v}} / 100\right)\right\}-C
$$

with $A=10.52, B=2484, C=263.1$

To analyze the performance of the heat pipe equipped heat exchanger, the heat flow rate as given by Eq. (3) is determined:

$$
Q=\dot{m} c_{p} \Delta T
$$

Here $\Delta T$ is the temperature difference in the airflow up- and downstream the heat exchanger. The heat loss to the environment was in separate measurements with a 
dedicated heat flux sensor measured to be less than $50 \mathrm{~W} / \mathrm{m}^{2}$. This is negligible as compared to the measured heat flow rates. In addition, differences between incoming and outgoing heat fluxes will be assessed below.

The effectiveness of the heat transfer at both the hot and cold side of the heat pipe heat exchanger is expressed in the overall heat transfer coefficient $\alpha_{\text {tot }}$ as defined by Eq. (4) [16]:

$$
\alpha_{\mathrm{tot}}=Q /\left(A \chi \Delta T_{\mathrm{lm}}\right)
$$

with $A$ the total heat transferring area to be specified below, $\chi$ a geometrical correction factor, here valued 1 [16], and with

$$
\Delta T_{\mathrm{lm}}=\left(\Delta T_{\max }-\Delta T_{\min }\right) / \ln \left(\Delta T_{\max } / \Delta T_{\min }\right)
$$

Here $\Delta T_{\max }$ and $\Delta T_{\min }$ denote the maximum and minimum temperature differences between the airflow and heat pipes of the first and last row. The area $A$ is either the area $A_{\text {fin,con }}$ on the condenser side $\left(24.3 \mathrm{~m}^{2}\right)$ or $A_{\text {fin,evap }}$ on the evaporator side $\left(38.6 \mathrm{~m}^{2}\right)$. Both $Q$ and $\alpha_{\text {tot }}$ will be used to assess the heat transfer performance of the heat exchanger.

\section{PREDICTION METHODS FROM THE LITERATURE}

A Nusselt number for heat transfer from the air to the fins is given by $N u=\alpha_{\text {fin }} D_{\mathrm{h}} / \lambda$ with the hydraulic diameter taken to be $2 S$, which is twice the distance between two neighbouring fin-plates (here $1.6 \mathrm{~mm}$ on the hot side and $2.6 \mathrm{~mm}$ on the cold side). Also 
the Reynolds number, $R e$, is based on the hydraulic diameter. Hewitt [17] provides the following correlation

$$
N u=0.19\left(\frac{a}{b}\right)^{0.2}\left(\frac{S}{d}\right)^{0.18}\left(\frac{h}{d}\right)^{-0.14} \operatorname{Re}^{0.65} \operatorname{Pr}^{0.33}=0.1124 \operatorname{Re}^{0.65}
$$

with $a$ the tube distance in a row (here $36.5 \mathrm{~mm}$ ), $b$ the distance between the tube in two successive rows (here $33.0 \mathrm{~mm}$ from heart-to-heart, see Fig. 2, and $27.5 \mathrm{~mm}$ in flow direction), $d$ the tube diameter (here $16 \mathrm{~mm}$ ) and $h$ the fin length in gas flow direction (here $13.7 \mathrm{~mm})$. The Prandtl number is nearly constant $(0.69-0.71)$, allowing for the last equality in (6).

The heat resistance of the wall of the heat pipe is given by

$$
R_{\mathrm{w}}=\frac{\ln \left(r_{\mathrm{o}} / r_{\mathrm{i}}\right)}{2 \pi \lambda_{\mathrm{w}} L_{\mathrm{cond}}}=\frac{1}{\alpha_{\mathrm{w}} A_{\mathrm{w}}}
$$

with $r_{\mathrm{o}}$ and $r_{\mathrm{i}}$ the outer and inner radii of the pipe (here $8 \mathrm{~mm}$ and $7.2 \mathrm{~mm}$, respectively), $\lambda_{\mathrm{w}}$ the thermal conductivity of the copper pipe and $L_{\mathrm{cond}}$ the length of the evaporator or the condenser section (here $640 \mathrm{~mm}$ ). Area $A_{\mathrm{w}}$ is taken to be given by $2 \pi r_{\mathrm{i}} L_{\mathrm{cond}}=0.029$ $\mathrm{m}^{2}$. The right hand side of Eq. (7) is obviously a (simple) implicit expression for the heat transfer coefficient $\alpha_{\mathrm{w}}$. The form of Eq. (7) is preferred since thermal resistances will be summed, in Eq. (12).

The heat transfer from the air to the tube is usually described with the fin efficiency [18] 
$\eta_{\text {fin }}=\tanh \left(m l_{\text {fin }}\right) /\left(m l_{\text {fin }}\right)$

with

$$
m=\left(\frac{2 \alpha_{\text {fin }}\left(1+\delta_{\text {fin }} / l_{\text {fin }}\right)}{\lambda_{\mathrm{f}} \delta_{\text {fin }}}\right)^{0.5}
$$

Every tube in the tube bank is supposed to have its own segment of fins. This leads to a fin length, $l_{\text {fin }}$, of half the distance between two tubes $(18.3 \mathrm{~mm})$; this $l_{\text {fin }}$ is the length from fin tip to tube wall. Furthermore, $\alpha_{\text {fin }}$ is the heat transfer coefficient from the air to the fin, given by Eq. (6), $\delta_{\text {fin }}$ the fin thickness, here $0.2 \mathrm{~mm}, \lambda_{\text {fin }}$ the thermal conductivity of the fin material, here aluminium, $236 \mathrm{~W} / \mathrm{mK}$. The total heat transferring area, $A$ in Eq. (4), is taken to be the heat transferring area of the fins; it is $24.3 \mathrm{~m}^{2}$ on the condenser side, where $A=A_{\text {fin,cond, }}$ and $38.6 \mathrm{~m}^{2}$ on the evaporator side, where $A=$ $A_{\text {fin,evap. }}$ This yields the following heat resistance between air and outer wall of the heat pipes [18]:

$$
R_{\text {fin }}=\frac{1}{\eta_{\text {fin }} \alpha_{\text {fin }} A_{\text {fin }}}
$$

The total heat transfer coefficient, is found from the summation of the partial heat resistances, which are given by Eqn. (7), (10) and one in the thermosyphon, $1 /\left(\alpha_{\mathrm{ff}} A_{\mathrm{w})}\right.$, see Fig. 3, that can be evaluated in a way described below. This yields, by definition of $\alpha_{\text {tot }}$ : 


$$
\alpha_{\mathrm{tot}}=\frac{1}{R_{\mathrm{tot}} A_{\mathrm{fin}}}
$$

with the total resistance given by

$$
R_{\mathrm{tot}}=\frac{1}{\alpha_{f f} A_{\mathrm{w}}}+\frac{1}{\alpha_{\mathrm{w}} A_{\mathrm{w}}}+\frac{1}{\eta_{f i n} \alpha_{\mathrm{fin}} A_{\mathrm{fin}}}
$$

Last but not least, $\alpha_{\mathrm{ff}}$ now needs to be evaluated.

The heat resistance of the condensate in the thermosyphon can be obtained from:

$$
R_{\mathrm{ff}, \mathrm{c}}=1 /\left(\alpha_{\mathrm{ff}, \mathrm{c}} A_{\mathrm{ff}, \mathrm{c}}\right)
$$

with $\alpha_{\mathrm{ff}, \mathrm{c}}$ a heat transfer coefficient, given below, and with $A_{\mathrm{ff}, \mathrm{c}}$ the wetted area inside the heat pipe at the condenser side, which will be taken to be equal to the full inside area at this side, $A_{\mathrm{w}}$. The analysis is therefore mainly applicable to fully wetting fluids; consistent with this assumption is the taking of $L_{\text {cond }}$ to be the full height of the condenser side, below.

The mean heat transfer coefficient at the condenser side, $\alpha_{\mathrm{ff}, \mathrm{c}}$, has been estimated using two correlations from the literature. The first one is the famous result of Nusselt's analysis of filmwise condensation on vertical plates [18, page 14.6]: 


$$
\alpha_{\mathrm{ff}, \mathrm{c}, 1}=1.47 \operatorname{Re}_{\mathrm{f}}^{-1 / 3}\left(\frac{\rho_{\mathrm{f}}\left(\rho_{\mathrm{f}}-\rho_{\mathrm{v}}\right) g}{\mu_{\mathrm{f}}^{2}}\right)^{1 / 3} \lambda_{\mathrm{f}}
$$

with $\rho_{\mathrm{v}}$ the mass density of the vapour and the film Reynolds number, $\mathrm{Re}_{\mathrm{f}}$, defined as:

$$
\operatorname{Re}_{\mathrm{f}}=4 \dot{m}_{\text {cond }} / \mu_{\mathrm{f}}
$$

The way the local mass flow rate per unit of periphery per tube, $\dot{m}_{\text {cond }}$, is evaluated will be described shortly. All fluid properties are evaluated at the saturation temperature corresponding to the prevailing pressure in the thermosyphon. The heat transfer coefficient given by Eq. (14) was proven to be in agreement with experiments in a wide range of flow and fluid conditions [18]. Typical film thicknesses, $\delta_{\mathrm{x}}$, have been computed and have been found to be two orders of magnitude less than the tube diameter, $d$. The correlation (14) for vertical flat plates is therefore applicable to our thermosyphons as well. The mass flow rate of liquid per unit of periphery per tube, $\dot{m}_{\text {cond }}$, needs to be that at the condenser end. Conservation of mass implies that the mass condensed at the total length of the condenser equals the film mass flow rate at the condenser end in steady operation. If $Q$ is the total heat flow rate to a total of $N$ tubes in the heat exchanger and $\Delta h_{\mathrm{fg}}$ the latent heat of the condensate, the mass flow rate $\dot{m}_{\text {cond }}$ is therefore given by

$$
\dot{m}_{\text {cond }}=Q /\left(N \pi d \Delta h_{\mathrm{fg}}\right)
$$


The present analysis aims at exploring the possibilities of existing, well-known correlations for predicting heat transfer in heat-pipe equipped exchangers. The Nusselt expression for the heat transfer coefficient was originally derived for laminar flow, but is here merely considered as a correlation. It could be extended with correction parameters to account for turbulence and/or waves on the vapour-liquid interface, see $[22,23,24]$ for example, but such extensions are only deemed necessary if agreement between measurement and prediction would turn out to be poor. For further comparison, a second correlation is examined.

Another way to compute the heat transfer coefficient for filmwise condensation is given by Rohsenow et al. [18,19]:

$$
\alpha_{\mathrm{ff}, \mathrm{c}, 2}=\left(\frac{\operatorname{Re}_{\mathrm{f}}}{1.08 \operatorname{Re}_{\mathrm{f}}^{1.22}-5.2}\right)\left(\frac{\rho_{\mathrm{f}}\left(\rho_{\mathrm{f}}-\rho_{\mathrm{v}}\right) g}{\mu_{\mathrm{f}}^{2}}\right)^{1 / 3} \lambda_{\mathrm{f}},
$$

with $\mathrm{Re}_{\mathrm{f}}$ in the range 30-1600. Estimates for $\mathrm{Re}_{\mathrm{f}}$ in our thermosyphons are in the range $30-100$.

In the evaporator pool boiling occurs. The Bond number, defined as

$$
B o=\sqrt{\rho_{\mathrm{f}} g d^{2} / \sigma}
$$

is typically in the range 16-34, which makes it unnecessary to account for the special effects that occur in confined boiling (Bo would need to be less than or around 1 for this to be the case). Even if the length scale in $B o$ would have been taken to be the width of small grooves $(2 \mathrm{~mm})$, the Bond number would still be exceeding 1 . The models of 
Cooper, see Eq.(19), and Gorenflo, see Eq.(20), predict the pool boiling heat transfer coefficient, $\alpha_{\mathrm{ff}, \mathrm{b}}[20]$.

$$
\alpha_{f f, b, 1}=55 p_{\mathrm{r}}^{0.12-0.4343 \ln \left(R_{p}\right)} \times\left(-0.4343 \ln \left(p_{\mathrm{r}}\right)\right)^{-0.55} M^{-0.5} q^{0.67}
$$

with $p_{\mathrm{r}}$ the reduced pressure, $p / p_{c}\left(p_{c}\right.$ is $4.06 \mathrm{MPa}$ for the fluid R-134a used here), $R_{p}$ surface roughness in $\mu \mathrm{m}$ (typically 1 ), $M$ molecular weight of the condensate in $\mathrm{kg} / \mathrm{kmol}$ (typically 102 for R-134a) and $q$ the heat flux.

$$
\alpha_{f f, b, 2}=4500 F_{P F}(q / 20000)^{0.9-0.3 p_{\mathrm{r}}^{0.3}} \times\left(R_{p} / 0.4\right)^{0.133}(20)
$$

with

$$
F_{P F}=1.2 p_{\mathrm{r}}^{0.27}+2.5 p_{\mathrm{r}}+p_{\mathrm{r}} /\left(1-p_{\mathrm{r}}\right)
$$

Of course, either $\alpha_{\mathrm{ff}, \mathrm{b}, 1}$ or $\alpha_{\mathrm{ff}, \mathrm{b}, 2}$ is to be taken for $\alpha_{\mathrm{ff}, \mathrm{b}}$, and $\alpha_{\mathrm{ff}}$ is given by $\alpha_{\mathrm{ff}, \mathrm{b}}$ at the evaporator side and by $\alpha_{\mathrm{ff}, \mathrm{c}}$ at the condenser side.

\section{RESULTS}

The measurements are performed at steady state, and it typically took 90 minutes to reach steady state condition. Measurements were done at each condition during 5 minutes to check steady state condition and to guarantee proper averaging. Figure 4 
shows a typical example of the airflow temperature histories during a measurement. This figure shows that the variation is less than $0.1^{\circ} \mathrm{C}$.

The heat flow rate is measured from the temperature difference over the heat exchanger both at the evaporator and condenser part of the heat pipe. At steady state these heat flow rates should be equal. Figure 5, with error bars to indicate the measurement error [15], shows the comparison of the heat flow rates at the evaporator side and condenser part of the experiments. This figure shows that the heat flow rate of evaporator is about $4 \%$ larger than the heat flow rate of the condenser, for which we have no explanation.

In some cases the heat flow rate is that high that the heat pipe can dry out. Ten Pt100's were mounted downstream the evaporator to measure the temperature distribution along the evaporator. Figure 6 shows four distributions at two process conditions for two filling degrees of the heat pipe. A local, nongradual increase in temperature along the evaporator indicates a dry-out. At dry-out, the inner wall of the thermosyphon is not fully covered with liquid. This occurs at low filling degree and high heat flow rate (Fig. 6). If dry-out occurs, the measurement is skipped from the analysis.

Figures 7 and 8 show the performance of the heat pipe at the evaporator side for various Reynolds numbers and filling degrees. The measurement error of the heat transfer coefficient [15] is about 7\%. In Fig. 7 the total heat transfer coefficient at $F_{e}$ of $19 \%$ is shown, whereas Fig. 8 shows results at the higher filling degree. The figures show that the performance increases with increasing heat flow rate. An increase of the Reynolds number of the airflow leads also to a better performance. Some process conditions have 
been repeated with a higher filling degree. The results are given in Fig. 8. A higher

filling degree gives a higher overall heat transfer coefficient at otherwise identical process conditions.

Figures 9 and 10 show the performance of the heat pipe at the condenser side for various Reynolds numbers and filling degrees. Fig. 9 presents the total heat transfer coefficient at $F_{e}$ of $19 \%$ and that of the filling degree of $59 \%$ is shown in Fig. 10. The figures show that the performance improves with increasing heat flow rate. As on the evaporator side, an increase of the Reynolds number of the airflow leads also to a better performance. Some process conditions have been repeated with a higher filling degree. The results are given in Fig. 10. A higher filling degree gives a higher overall heat transfer coefficient at some process conditions. The Figs. 7-10 show that the performance of the condenser is better than that of the evaporator at the same heat flow rate, if performance is measured in terms of net heat transfer coefficient.

\section{ANALYSIS}

The trend of the heat transfer coefficient to level off and even to decrease with increasing heat flow rate, most clearly seen at $F_{e}=59 \%$ in Figure 8, was by Hahne and Gross [21] only found for angles of inclination (from the vertical) exceeding 40 degrees. The more horizontal, the more pronounced this effect was, and their explanation was vapour blanketing at one side of the thermosyphon ${ }^{\dagger}$. The present measurements are in a vertical thermosyphon, and the observed trend is found to be more pronounced at the higher filling ratio. Probably vapour blocking again plays a role, and this phenomenon

\footnotetext{
$\dagger$ The force interpretation given by Hahne and Gross is incomplete: inertia forces are not merely in the main flow direction since bubbles growing at a wall experience inertia forces in other directions as well.
} 
is expected to manifest itself only if sufficient fluid is present. Park et al. [22, Figure 4] found for heat flow rates to a smooth tube (and PFC, $\mathrm{C}_{6} \mathrm{~F}_{14}$, as working fluid) a similar dependence on evaporating heat flux, and a similar dependence on filling ratio.

Figures 11 and 12 show a comparison of the measured total heat transfer coefficient and predictions based on models of pool boiling of Gorenflo and Cooper [20], see section 3. Fig. 11 shows the comparison at airflow Reynolds number (based on $2 S$ ) of $250( \pm 2)$ whereas Fig. 12 presents the comparison at $R e=800( \pm 8)$. In both cases the Gorenflo correlation predicts a higher heat transfer coefficient than Cooper. Both correlations yield the same trend with respect to dependency on heat flux as the corresponding measurements, and the agreement with measurements is quite good for each Reynolds number. The small differences between the two models and the measurements could be caused by a slight overestimation of the Nusselt number for the airflow to the fins. If the temperature is not homogenously distributed the Nusselt number should be lower than the estimated one. The heat transfer estimate from the air to the fins has a large influence on the total heat transfer, so any inaccuracy in it is directly reflected in comparisons like those of Figs. 11-12.

The best predictions are obtained with correlations for boiling in the heat pipe (Gorenflo or -even better- Cooper). The use of well-established correlations as those of Cooper has usually led to good agreement between measurement and prediction of heat transfer in a thermosyphon, see for example [21, 22, 25].

Figures 13 and 14 show a comparison of the measured total heat transfer coefficient and predictions based on models of filmwise condensation of Butterworth and Nusselt [15], 
see section 3. Fig. 13 shows the comparison at airflow Reynolds number 400 whereas

Fig. 14 presents the comparison at $R e=800$. Fig. 13 shows a good agreement between the predictions and the measurements. At higher airflow Reynolds numbers the difference between prediction and measured heat transfer coefficient increases a bit (Fig. 14) and in this case the models underpredict the actual heat transfer. Similar to the evaporation side the difference might be due to the estimation of the Nusselt number for the airflow to the fins. However, at both Reynolds numbers the predicted heat flux decreases with increasing heat flow rate, which is a different trend than the one measured. This measured trend is in agreement with measurements reported by Hahne and Gross [21] for the heat transfer coefficients $\alpha_{\mathrm{ff}}$ of R115. The more vertical the thermosyphon, the bigger the increase of $\alpha_{\mathrm{ff}}$ with increasing heat flow rate. This indicates that distribution phenomena along the circumference play a role, something that is not captured by the correlations of Butterworth and Nusselt, of course.

\section{CONCLUSIONS}

The performance of a heat pipe equipped heat exchanger for air has been measured and analyzed. The heat pipe has no wick, so it is a thermosyphon, and is long compared to its diameter: $150 \mathrm{~cm}$ vs. $1.6 \mathrm{~cm}$. No measurements with thermosyphons that long have been found in literature except those of Noie [1] with a multi-row heat pipe heat exchanger with a thermosyphon length of $130 \mathrm{~cm}$ and except those with a single tube of $0.8 \mathrm{~m}$ in reference [26]. The overall heat transfer of the heat exchanger has been assessed. At the evaporator side 10 to $40 \mathrm{~W} / \mathrm{m}^{2} \mathrm{~K}$ has been measured and at the condenser side of the heat pipe 20 to $50 \mathrm{~W} / \mathrm{m}^{2} \mathrm{~K}$. The temperature distribution over the evaporator has been found to be indicative of proper filling degree. 
A model to predict the heat transfer and to calculate the performance of the heat pipe equipped heat exchanger based on correlations from literature has been presented. This model yields good agreement between experiments and predictions. Trends have been interpreted with the aid of various findings reported with single-tube thermosyphons.

The result of this study is that a heat pipe equipped heat exchanger can replace a watercooled heat exchanger without loss of performance. The tested process conditions are typical for warmer countries like Bahrain. This study therefore demonstrates that it is possible to apply heat-pipe-based cooling equipment in practical conditions of warmer countries. More research has to be carried out to find, for example, the most suitable working fluid, the optimal heat pipe geometry, operating limits.

\section{ACKNOWLEDGMENT}

We are obliged to VDL Klima b.v., the Netherlands, for financial support and to one of the reviewers for useful suggestions. 


\section{REFERENCES}

[1] S.H. Noie, Investigation of thermal performance of an air-to-air thermosyphon heat exchanger using \&-NTU method, Applied Thermal Engineering 26 (5-6) (2006) 559567.

[2] S.H. Noie-Baghban, G.R. Majideian, Waste heat recovery using heat pipe heat exchanger (HPHE) for surgery rooms in hospitals, Applied Thermal Engineering 20 (14) (2000) 1271-1282.

[3] L.L. Vasiliev, Heat pipes in modern heat exchangers, Applied Thermal Engineering 25 (1) (2005) 1-19.

[4] L.L. Vasiliev, State-of-the-art on heat pipe technology in former Soviet Union, Applied Thermal Engineering 18 (7) (1998) 507-551.

[5] P.D. Dunn, D.A. Reay, Heat pipes, fourth ed., Pergamon, 1994.

[6] T. Wadowski, A. Akbarzadeh, P. Johnson, Characteristics of a gravity assisted heat pipe based heat exchanger, Heat Recovery Systems \& CHP 11 (1) (1991) 69-77.

[7] M.J. Morgan, H.N. Shapiro, Fundamentals of Engineering Thermo-dynamics, 2nd ed., John Wiley \& Sons Inc., 1992.

[8] NIST Standard Reference Database 69, June 2005 Release, NIST Chemistry WebBook.

[9] J. Unk, Ein Beitrag zur Theorie des geschlossenen Zweiphasen-Thermosiphons, Dissertation Technische Universität Berlin, 1988.

[10] A.P. Fröba, L. Penedo Pellegrino, A. Leipertz, Viscosity and Surface Tension of Saturated n-Pentane, International Journal of Thermophysics 25 (2004) 1323-1337. 
[11] A.P. Fröba, S. Will, A. Leipertz, Saturated liquid viscosity and surface tension of alternative refrigerants, 14th Symposium on Thermophysical Properties, Boulder, Colorado, U.S.A., 2000.

[12] D.A. Reay, Heat exchanger selection part 4: Heat pipe heat exchangers, Int. Research \& Development Co. Ltd., 1984.

[13] H.S. Lee, J.L. Yoon, J.D. Kim, J.D., Pradeep Bansal, Evaporating heat transfer and pressure drop of hydrocarbon refrigerants in 9.52 and $12.70 \mathrm{~mm}$ smooth tube, International Journal of Heat and Mass Transfer 48 (12) (2005) 2351-2359. [14] S.H. Noie, Heat transfer characteristics of a two-phase closed thermosyphon, Applied Thermal Engineering 25 (4) (2005) 495-506.

[15] S.J. Kline, F.A. McKlintock, Describing uncertainties in single-sample experiments, Mechanical Engineering 75 (1953) 3-8.

[16] VDI-Wärmeatlas, Berechnungsblaetter fuer den Waermeuebergang, 6. erw. Auflage, VDI Verlag GmbH., 1991.

[17] G.F. Hewitt, Heat Exchanger Design Handbook, Begell House, 1998.

[18] W.M. Rohsenow, J.P. Hartnett, Y.I. Cho, Y. I., Handbook of Heat Transfer, third ed., McGraw-Hill, 1998.

[19] H.D. Baehr, K. Stephan, Heat and Mass Transfer, Springer, 1998.

[20] J.G. Collier. J.R. Thome, Convective boiling and condensation, Clarendon Press, 1994.

[21] E. Hahne, U. Gross, The influence of the inclination angle on the performance of a closed two-phase thermosyphon, Heat Recovery Systems 1 (1981) 267-274. 
[22] Y.J. Park, H.K. Kang, C.J. Kim, Heat transfer characteristics of a two-phase closed thermosyphon to the fill charge ratio, Int. J. of Heat and Mass Transfer 45 (2002), 46554661.

[23] S. Thumm, Ch. Phillipp, U. Gross, Film condensation of water in a vertical tube with countercurrent vapour flow, Int. J. of Heat and Mass Transfer 44 (2001), p. 42454256.

[24] S. G. Kandlikar, Handbook of phase change, Boiling and Condensation, Taylor and Francis, 1999.

[25] E. Azad, F. Geoola, A design procedure for gravity-assisted heat pipe heat exchanger, Heat Recovery Systems 4 (2) (1984), 101-111.

[26] K.S. Ong, Md. Haider-E-Alahi, Performance of a R-134a-filled thermosyphon, Applied Thermal Engineering 23 (18) (2003) 2373-2381. 


\section{Figure captions}

Fig. 1. Schematic of the test rig.

Fig. 2. Definition of temperatures in air streams and tube arrangement.

Fig. 3. Schematic of heat transfer areas and resistances.

Fig. 4. Typical histories of air temperatures, see also Fig. 2, up- and downstream of the heat exchanger. Mean values are $T_{3}=78.21 \pm 0.03^{\circ} \mathrm{C}, T_{4}=60.84 \pm 0.02^{\circ} \mathrm{C}, T_{1}=24.76 \pm$ $0.03^{\circ} \mathrm{C}$ and $T_{2}=40.13 \pm 0.02^{\circ} \mathrm{C}$.

Fig. 5. Comparison of measured heat flow rates at evaporator and condenser side of the heat pipe.

Fig. 6. The effect of filling degree and of mass flow rate on temperature distribution downstream of the evaporator.

Fig. 7. Measured heat transfer coefficient evaporator side for various Reynolds numbers at $F_{e}=19 \%$.

Fig. 8. Measured heat transfer coefficient evaporator side for various Reynolds numbers at $F_{e}=59 \%$.

Fig. 9. Measured heat transfer coefficient condenser side for various Reynolds numbers at $F_{e}=19 \%$.

Fig. 10. Measured heat transfer coefficient condenser side for various Reynolds numbers at $F_{e}=59 \%$.

Fig. 11. Comparison of measured and predicted total heat transfer coefficient of the evaporator at $F_{e}=19 \%$ and at airflow Reynolds number of 250 .

Fig. 12. Comparison of measured and predicted total heat transfer coefficient of the evaporator at $F_{e}=19 \%$ and at airflow Reynolds number of 800 . 
Fig. 13. Comparison of measured and predicted total heat transfer coefficient of the condenser at $F_{e}=19 \%$ and at airflow Reynolds number of 400 .

Fig. 14. Comparison of measured and predicted total heat transfer coefficient of the condenser at $F_{e}=19 \%$ and at airflow Reynolds number of 800 . 


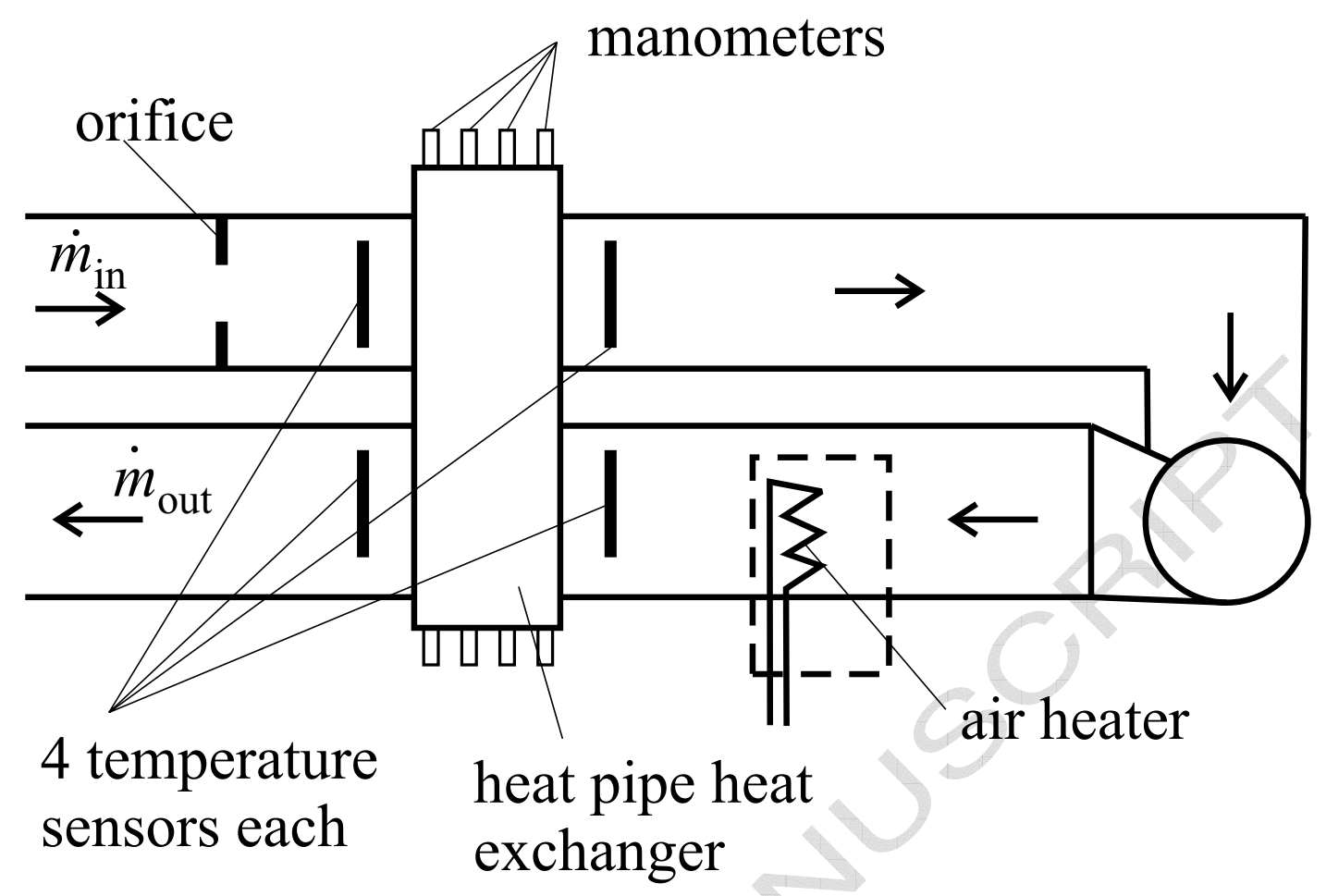

Fig. 1. 


\section{ACCEPTED MANUSCRIPT}

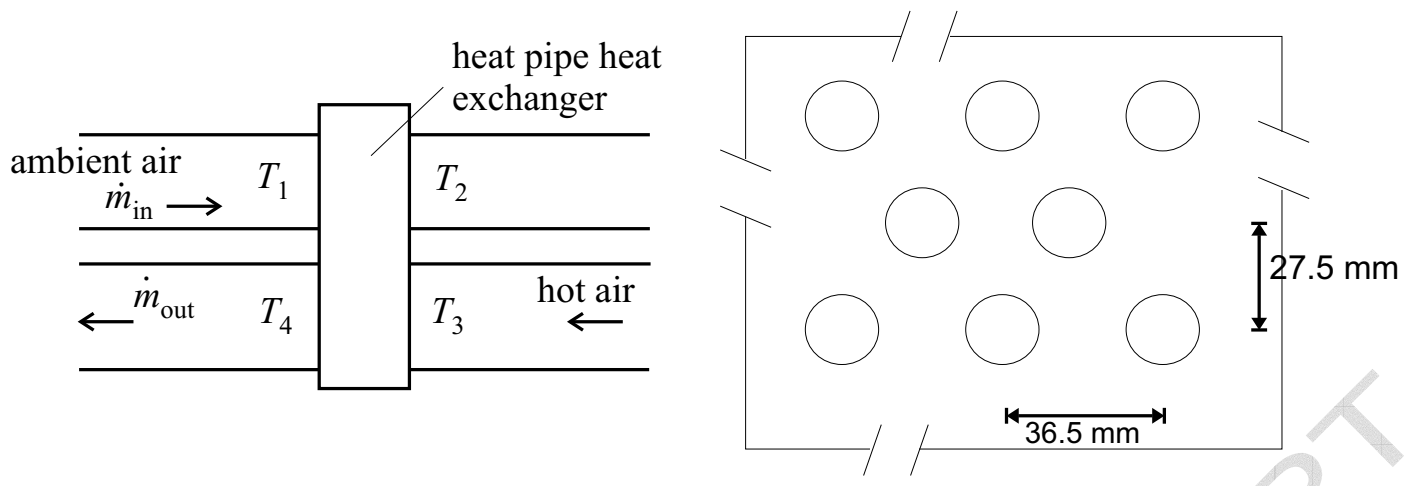

Fig. 2. 


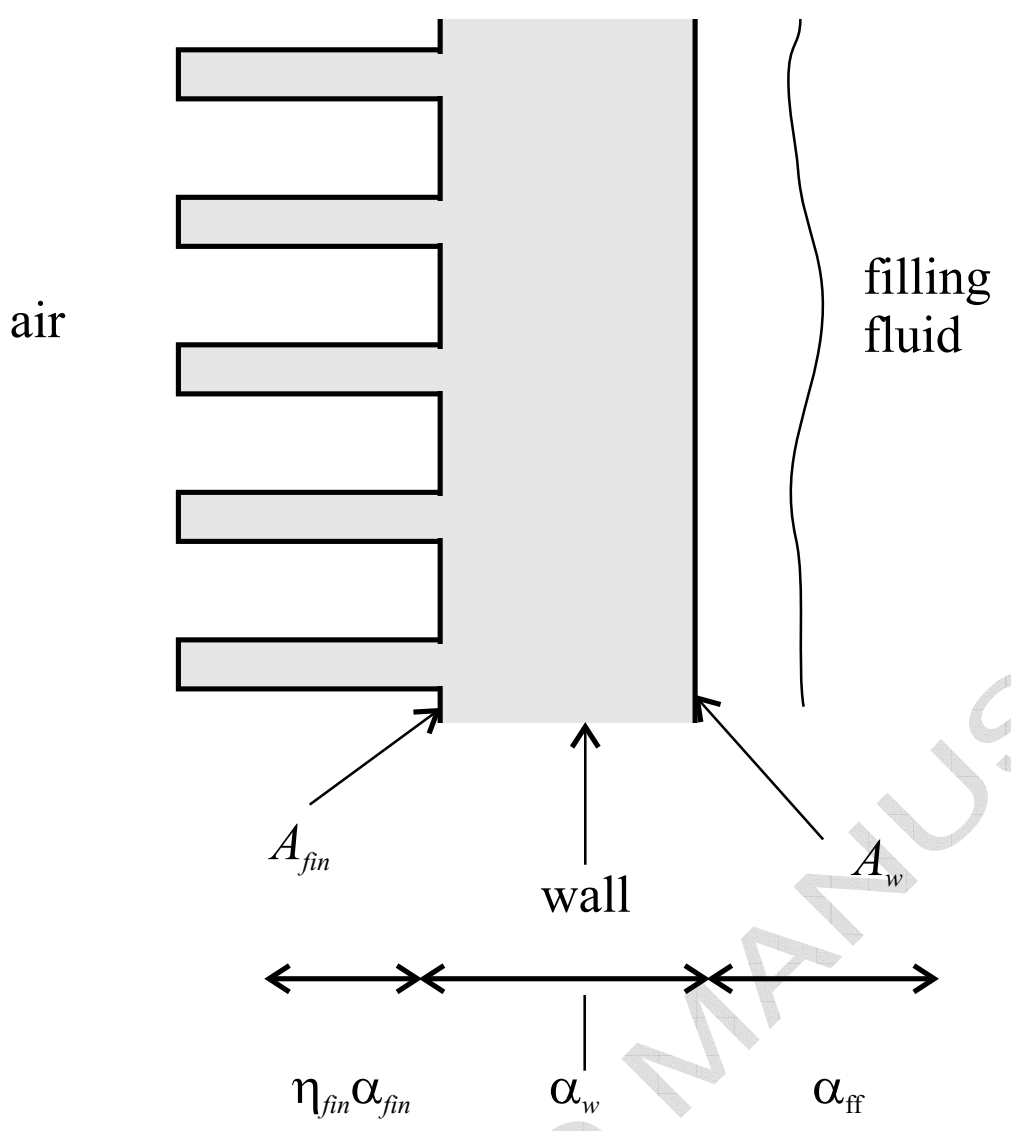

Fig. 3. 


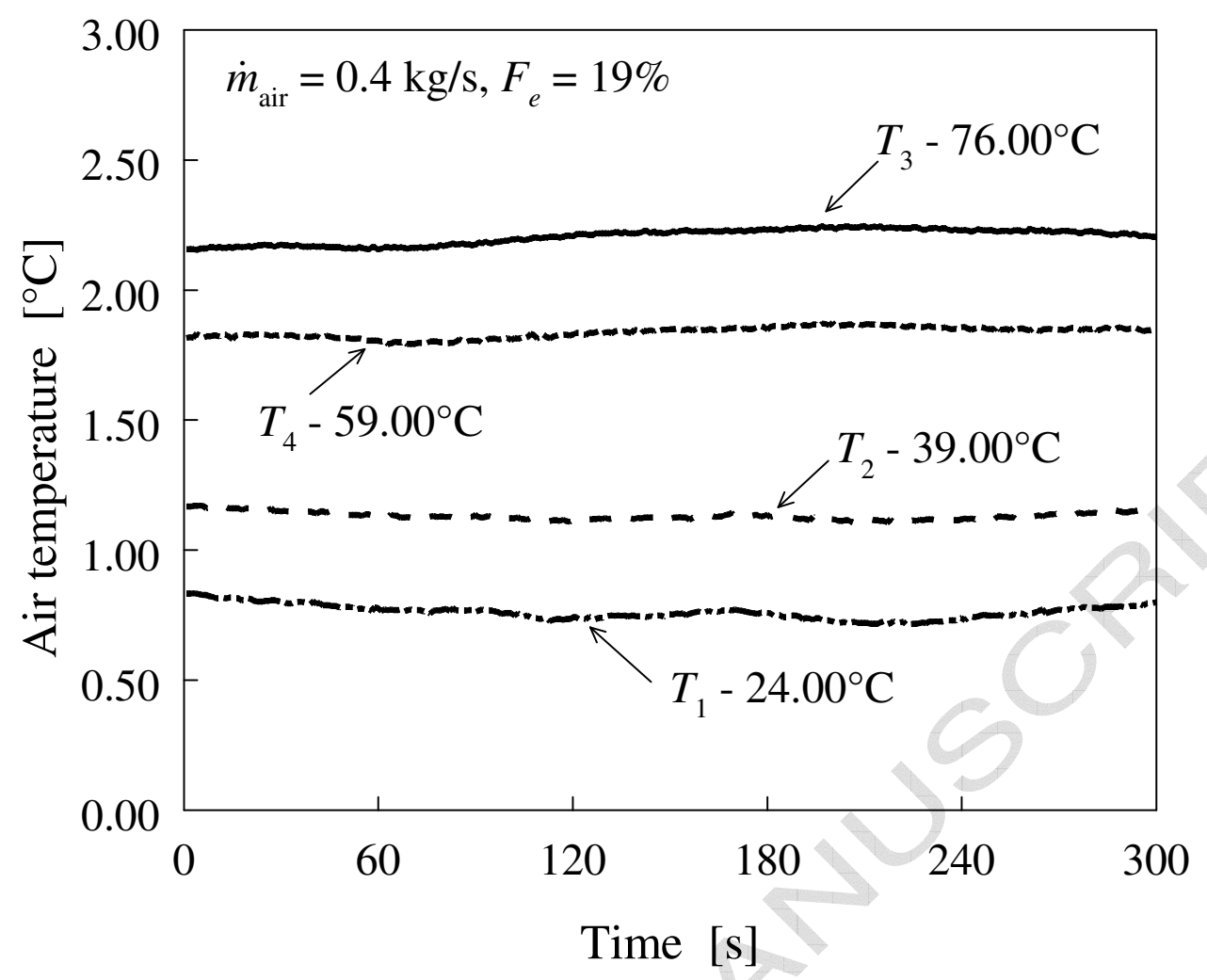

Fig. 4. 


\section{ACCEPTED MANUSCRIPT}

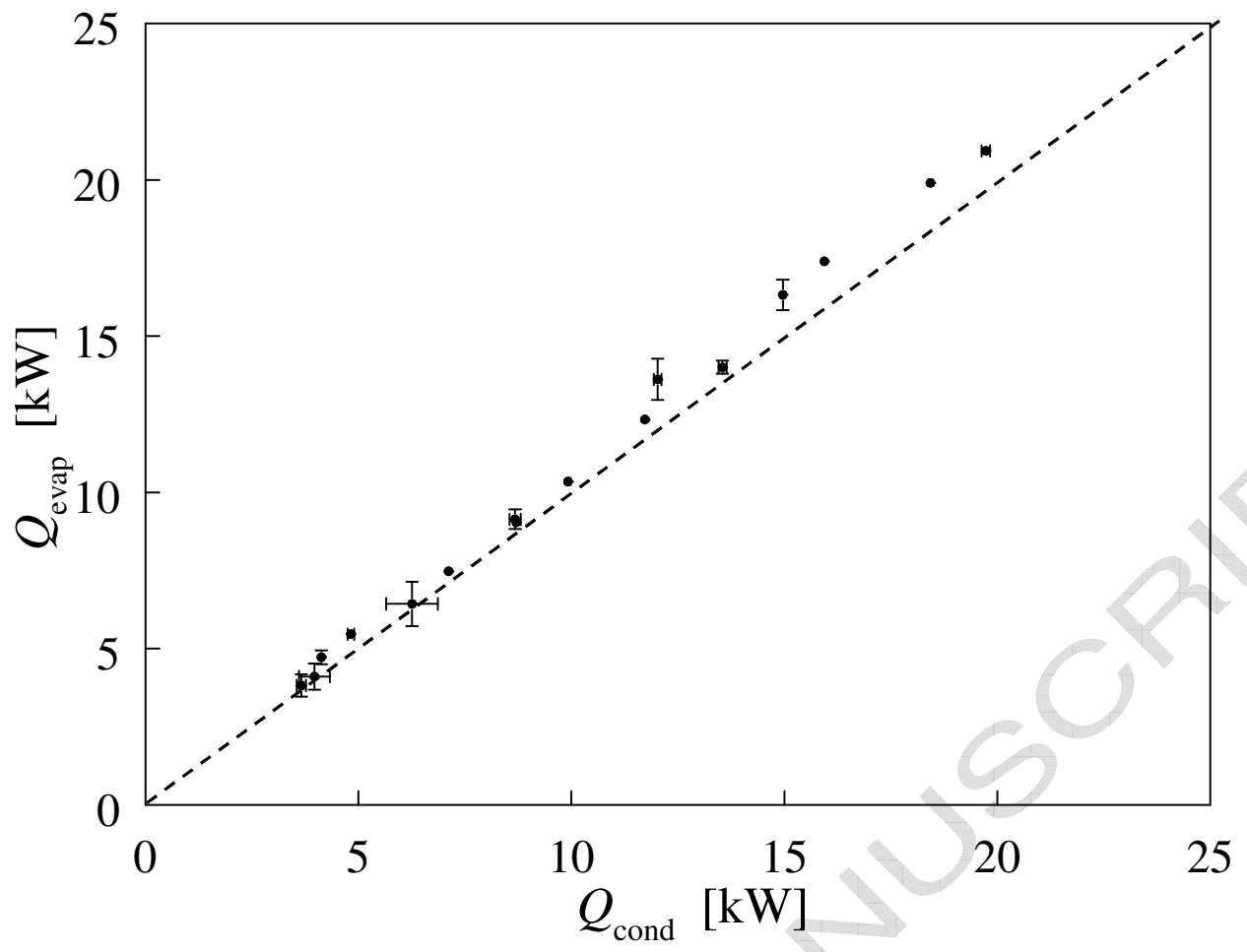

Fig. 5. 


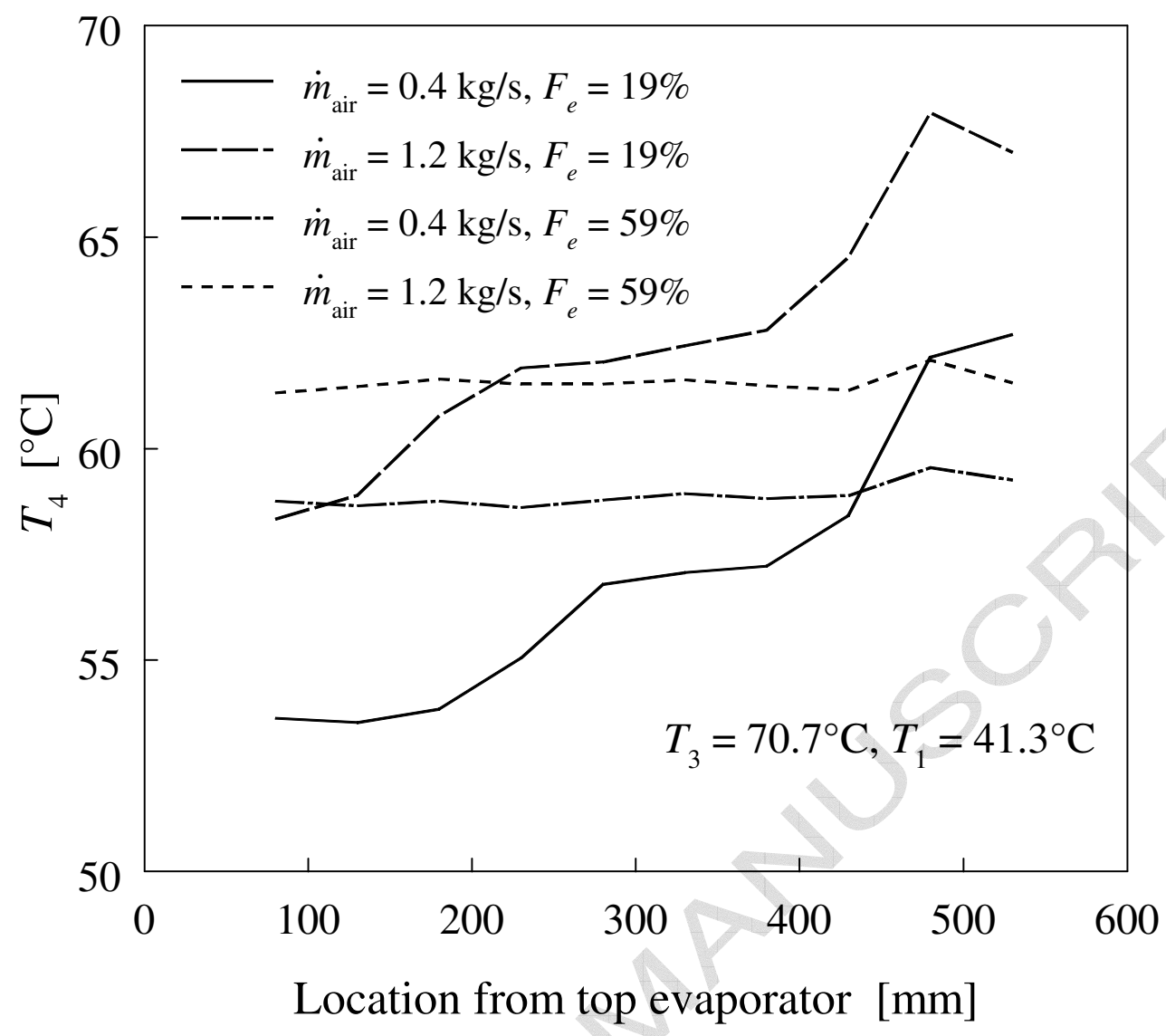

Fig. 6. 


\section{ACCEPTED MANUSCRIPT}

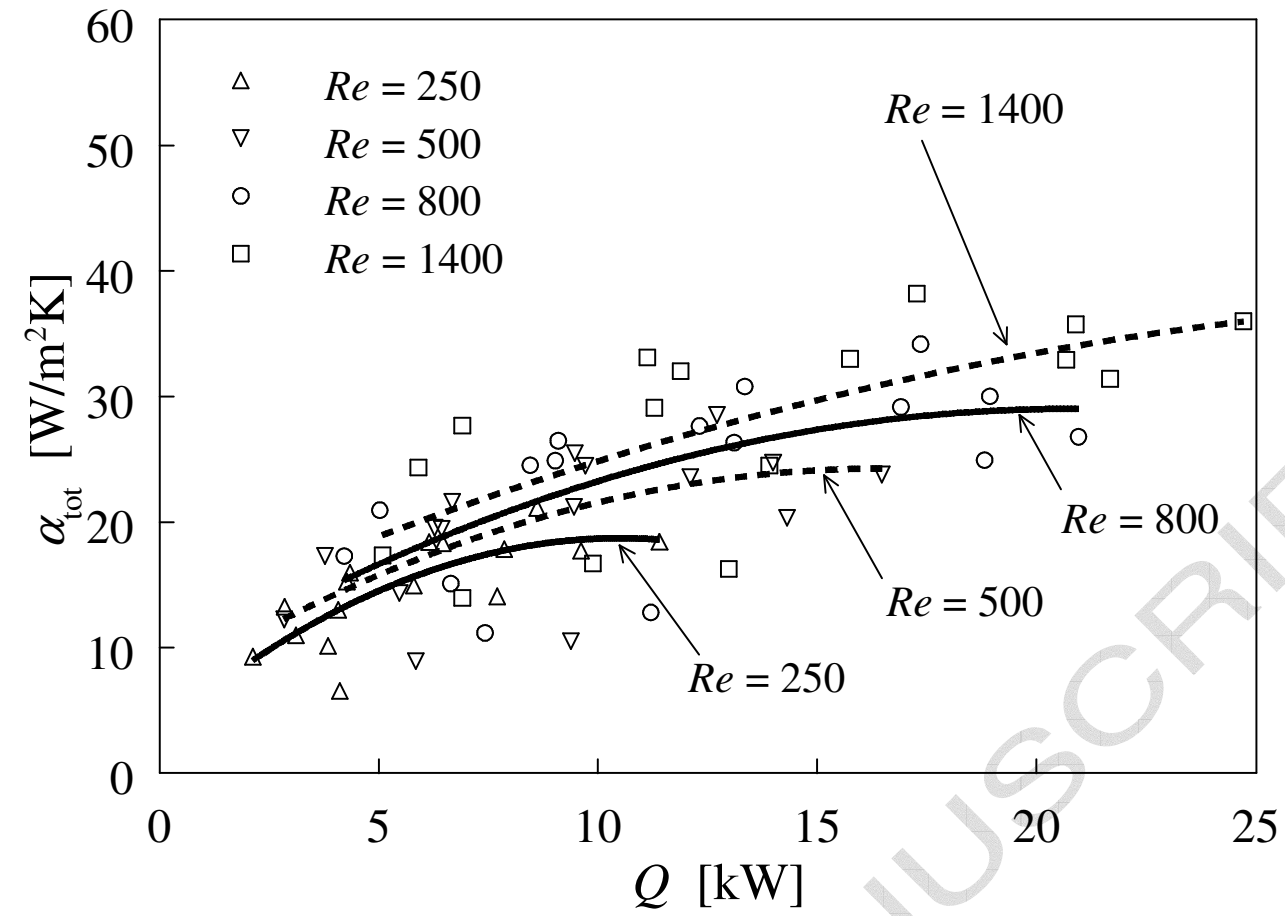

Fig. 7. 


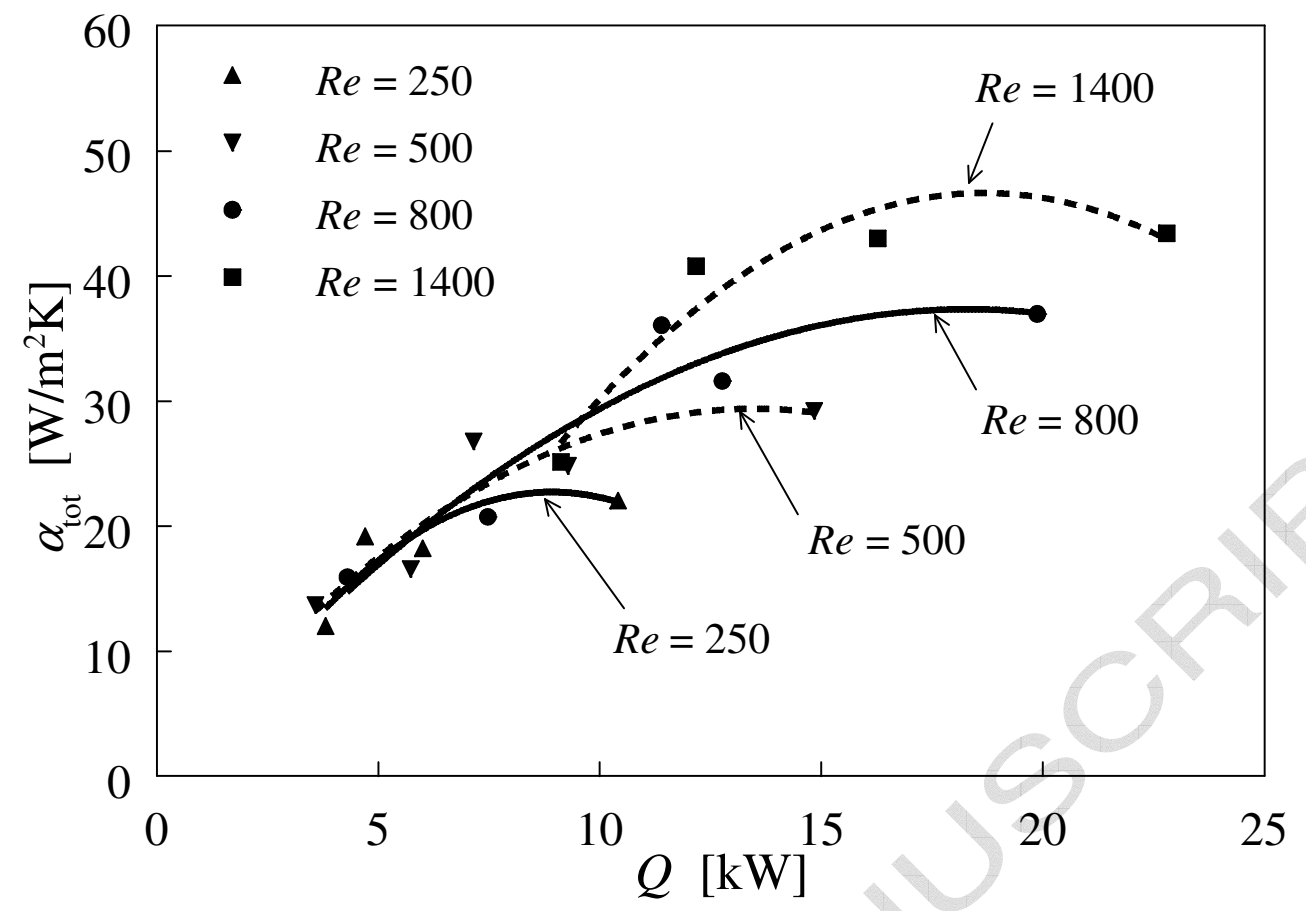

Fig. 8. 


\section{ACCEPTED MANUSCRIPT}

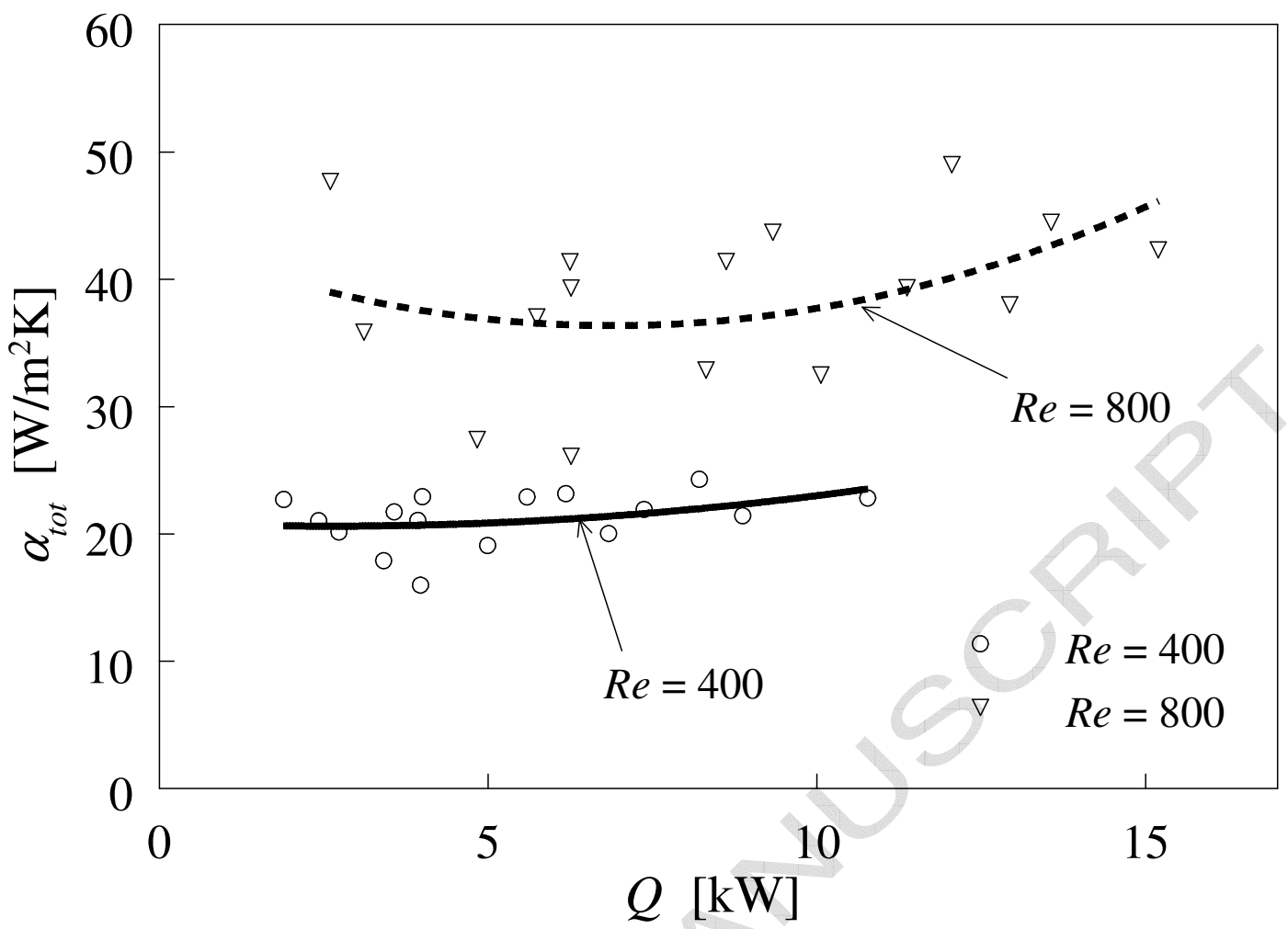

Fig. 9. 


\section{ACCEPTED MANUSCRIPT}

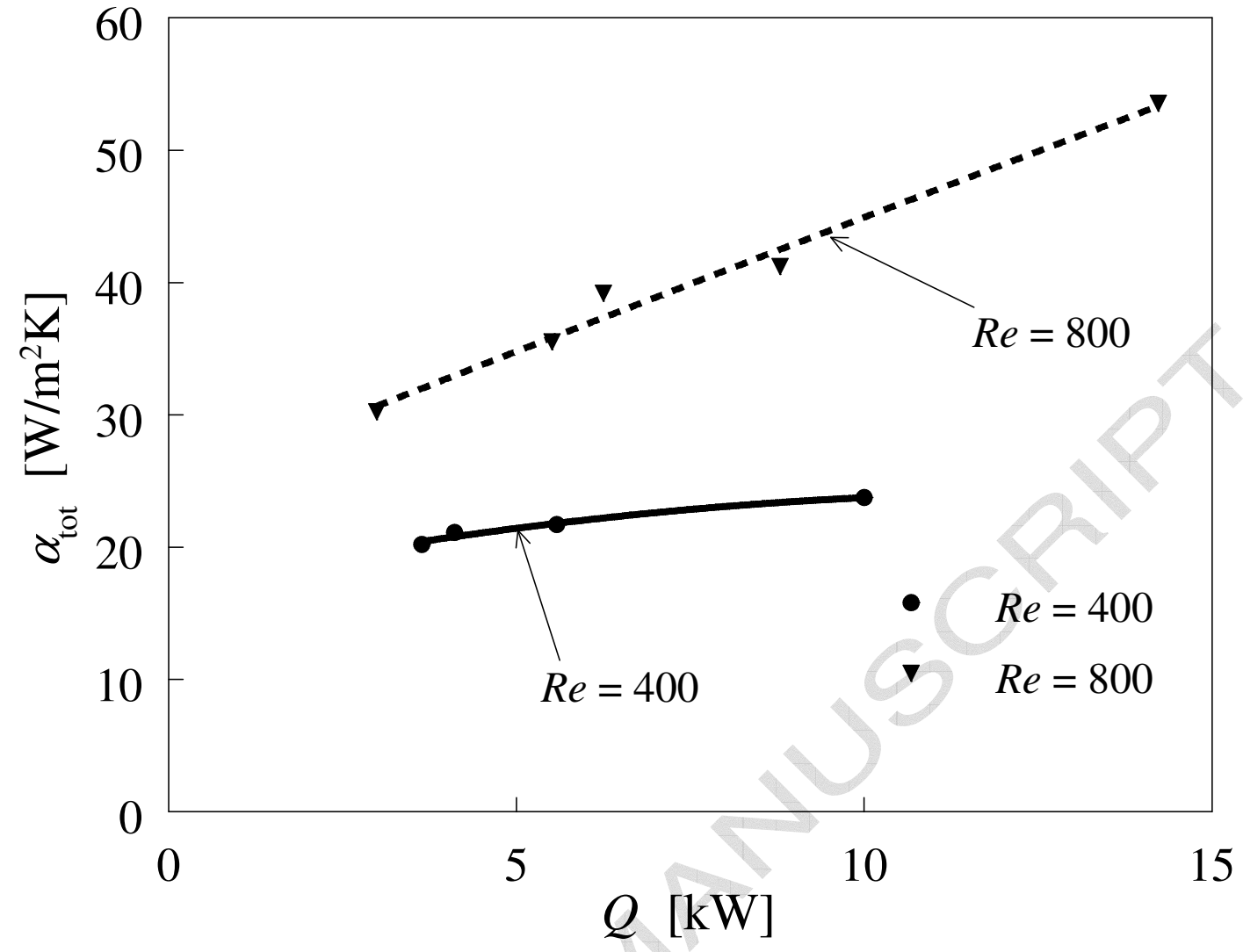

Fig. 10. 


\section{ACCEPTED MANUSCRIPT}

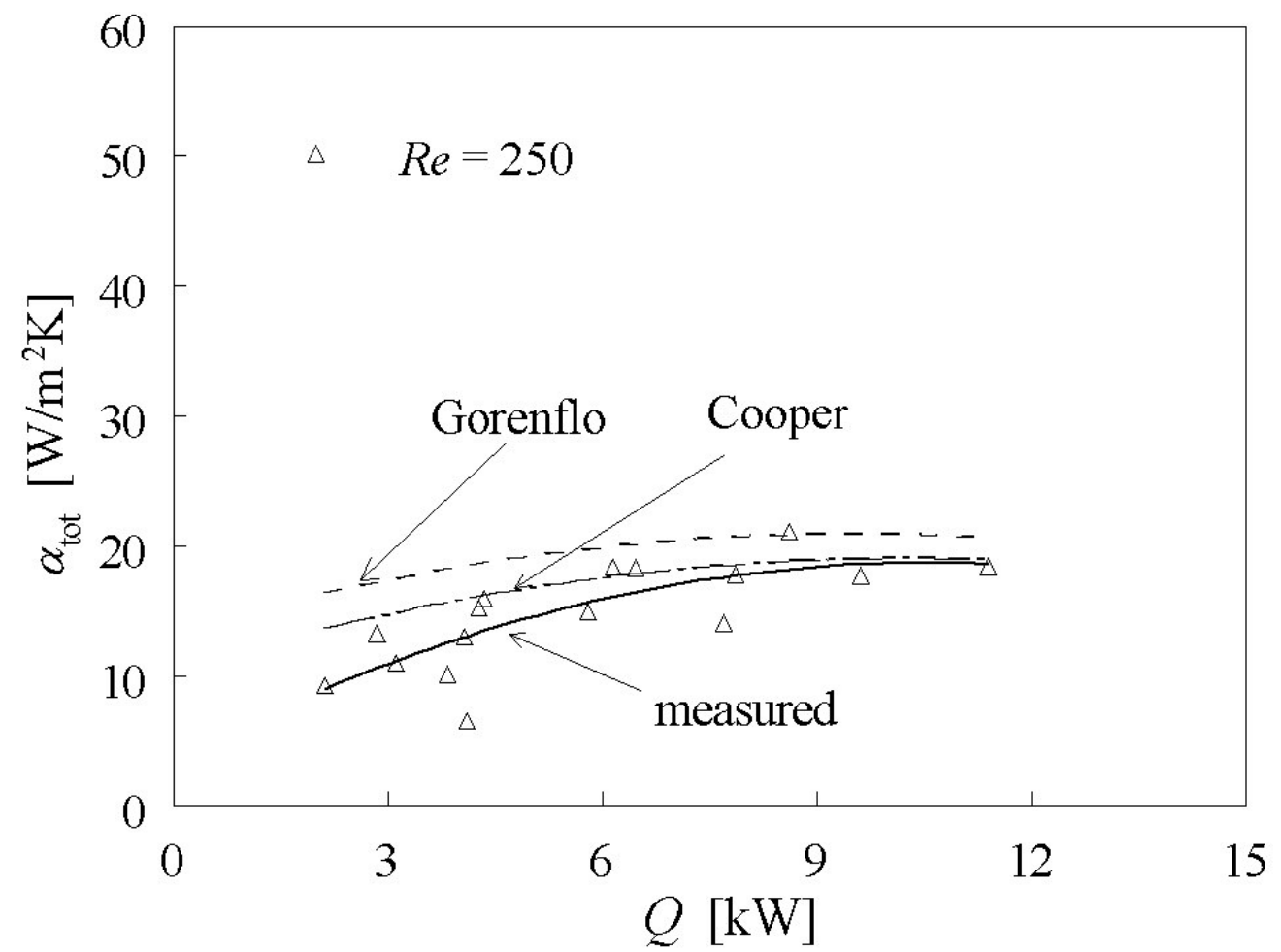

Fig. 11. 


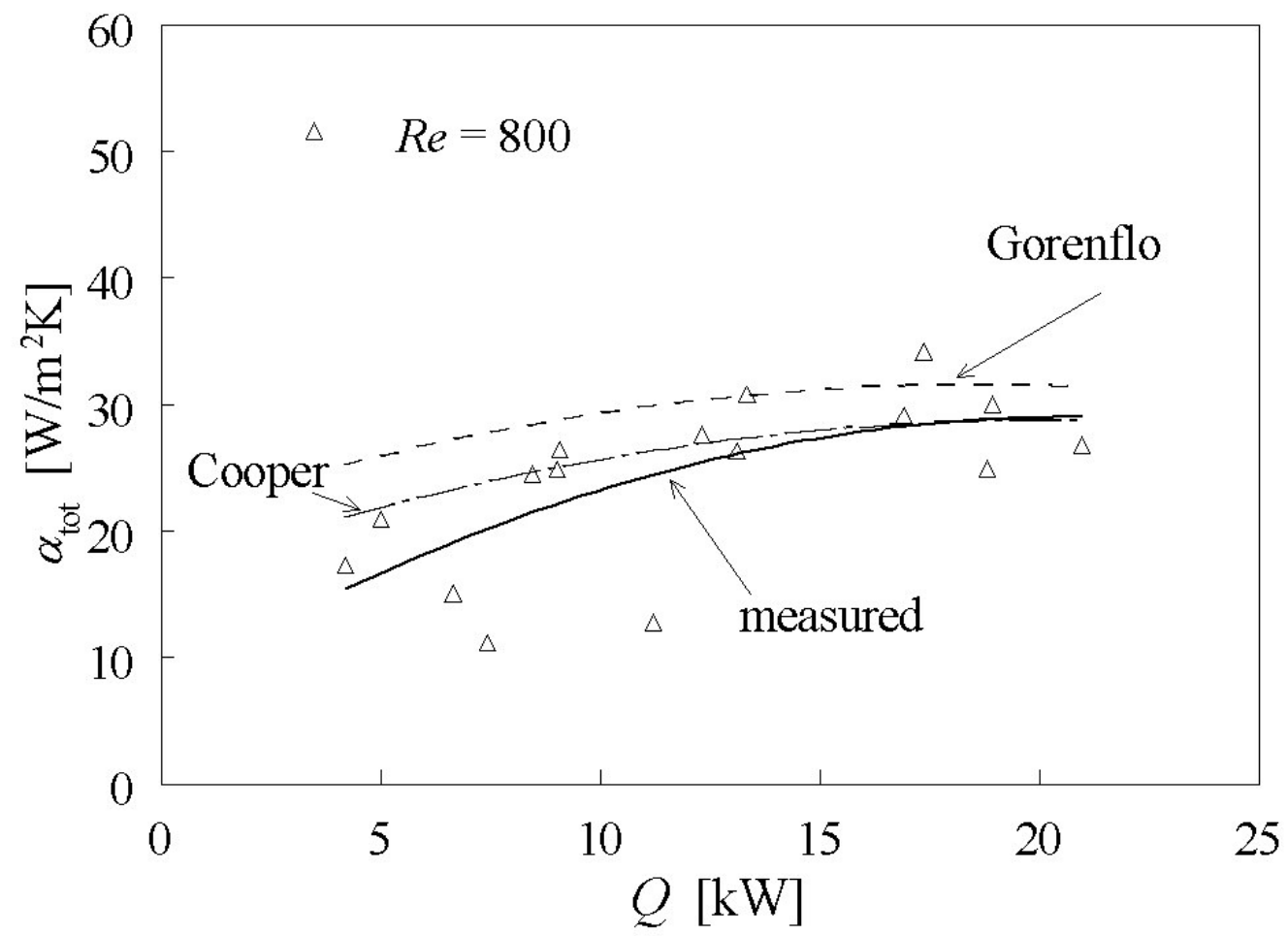

Fig. 12. 


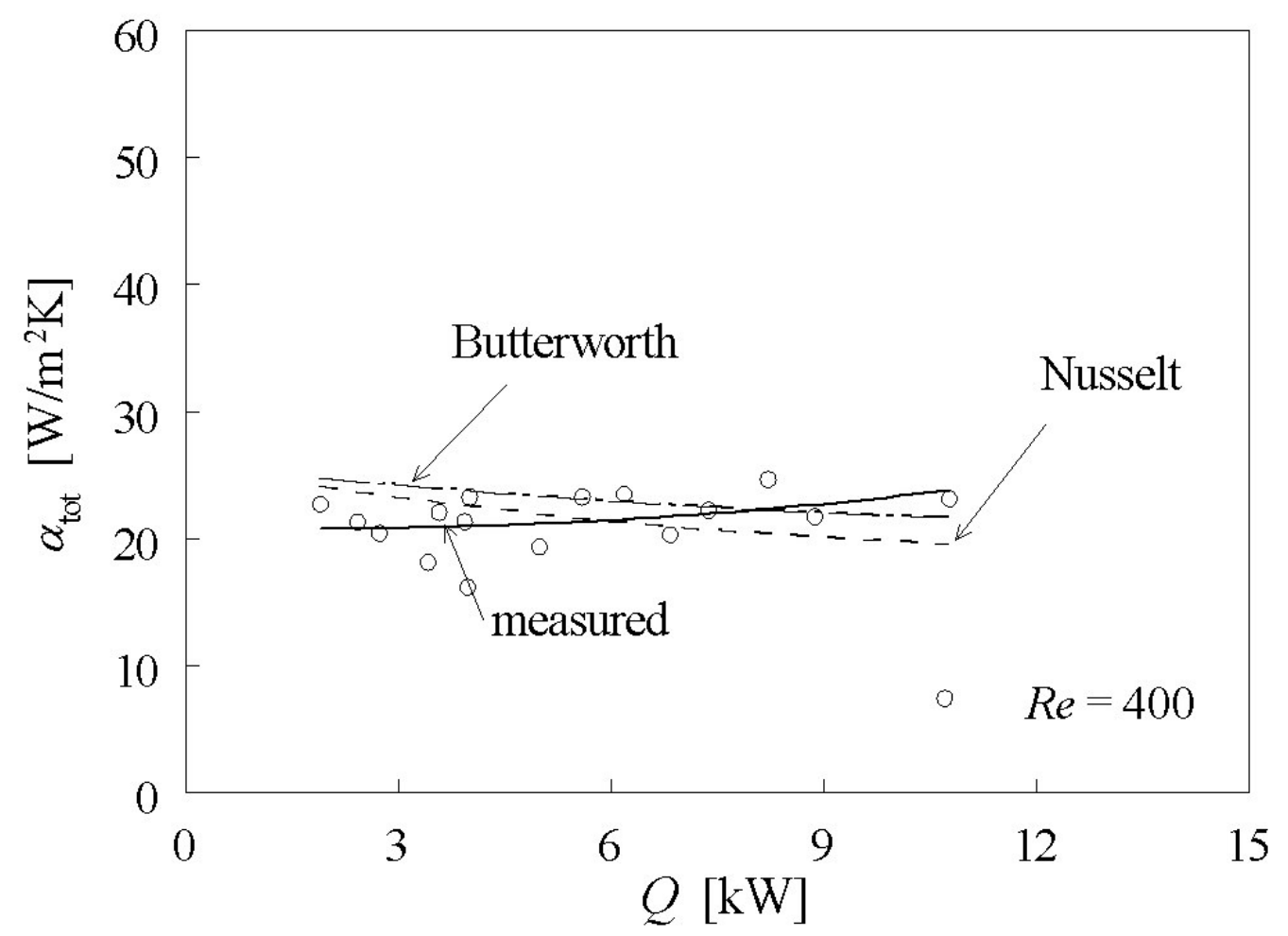

Fig. 13. 


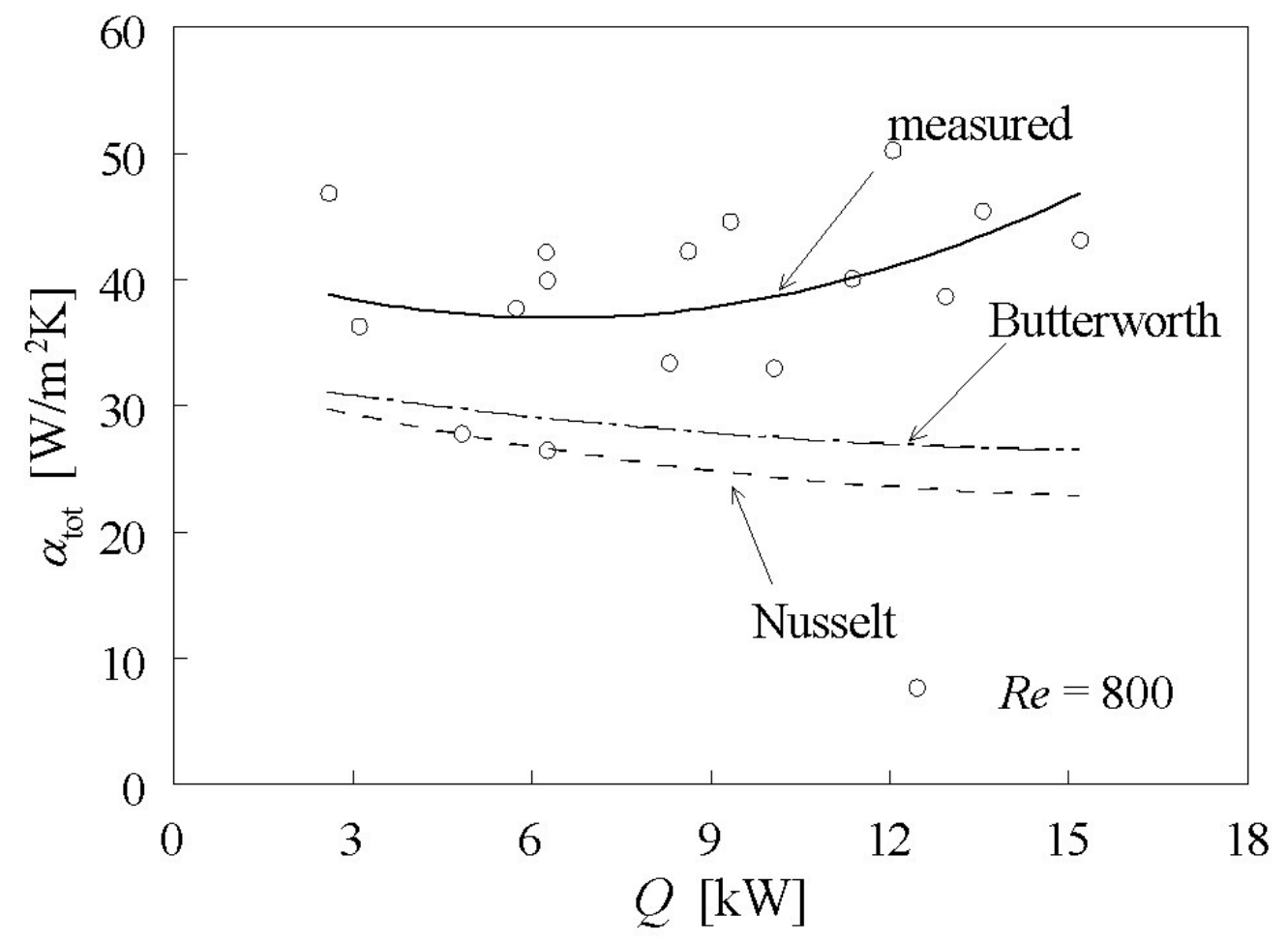

Fig. 14. 